\title{
Impact of Different Time of Use Electricity Pricing Structure on Residential Consumer
}

\author{
Nur Azrina Mohd Azman', Md Pauzi Abdullah², Mohammad Yusri Hassan³, Dalila Mat Said ${ }^{4}$, \\ Faridah Hussin $^{5}$, Norzanah Rosmin ${ }^{6}$, Siti Maherah Hussin ${ }^{7}$ \\ 1,2,3,4,5,6,7 Faculty of Electrical Engineering, Universiti Teknologi Malaysia, 81310 Johor Bahru, Malaysia \\ 2,3,4,5,6,7 Centre of Electrical Energy Systems, Institute of Future Energy, Universiti Teknologi Malaysia, 81310 Johor \\ Bahru, Malaysia
}

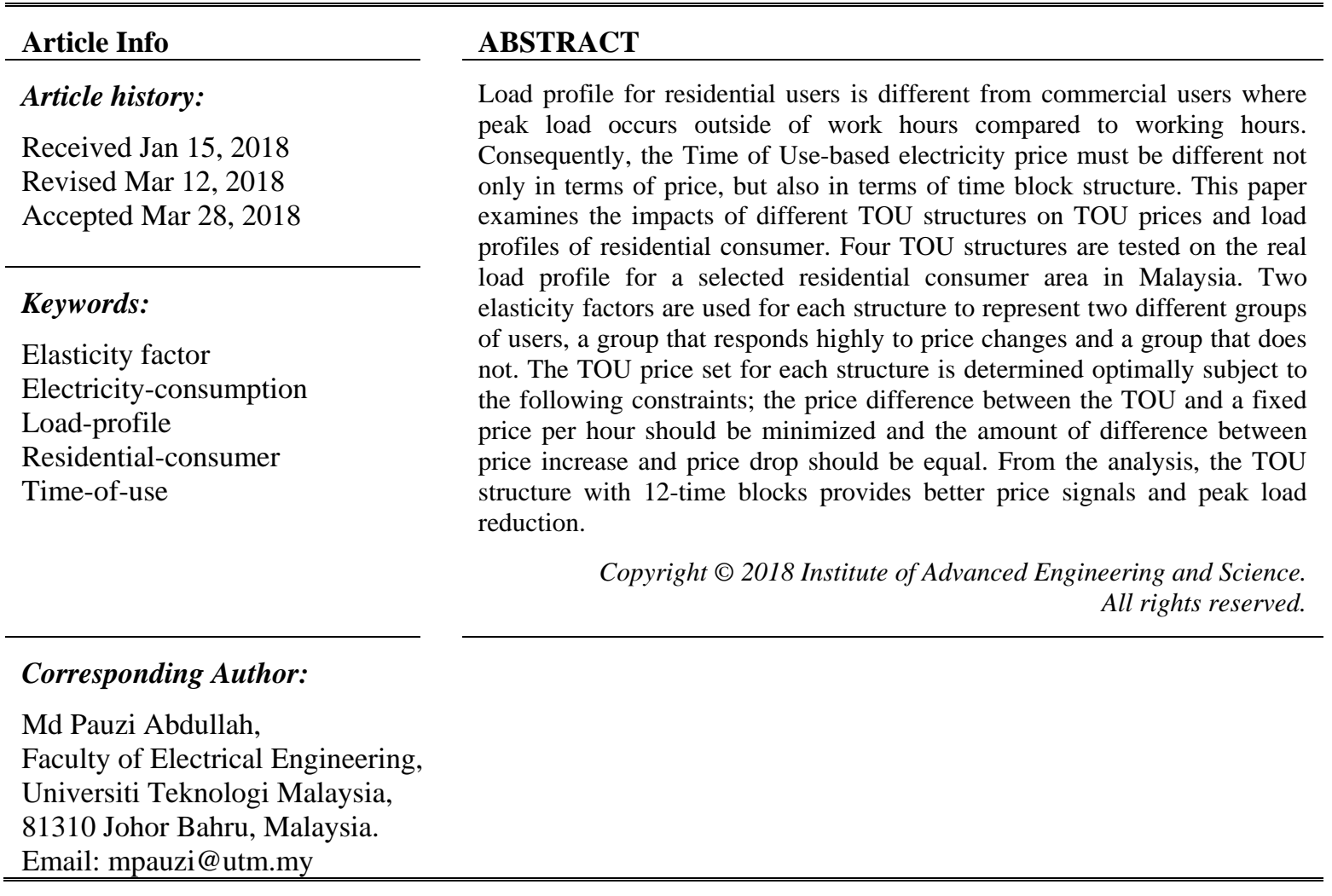

\section{INTRODUCTION}

The total cost of generating electricity for a power system is different at all times. In general, these costs are high at peak times and low at non-peak times. Thus, the use of fixed electricity price tariffs does not reflect actual electricity prices. It is possible for users paying lower prices at peak times and pay much higher prices outside peak hours. While the real-time electricity pricing method can overcome this problem, its implementation is complicated as it requires the use of smart meters among consumers to enable real-time electricity pricing information to be delivered from the utility to consumers. The price fluctuations that are too frequent are also inconvenient to users.

Time of Use (TOU) electricity tariff is one type of time-based tariff system. It charges consumer based on their usage hour with different price. It is known that demand response can efficiently help reducing peak demand in daily consumption [1]. However, differing from Real Time Pricing varies all the time based on the wholesale market price, TOU prices is fixed within the same period. It often refers to pre-set electricity prices that vary from time to time to reflect the expected cost of electricity generation at those times. Although TOU cannot reflect the actual price as much as real-time electricity prices, it's much better than fixed price rates that gives a flat price to the consumers every single hour [2]. The main objective of TOU implementation is to reduce the system's maximum demand by transferring some of the demand into 
different hours. In other words, to reduce the gap between peak and off-peak demand to gain flatter load profile.

Malaysian electrical utility company i.e. TNB only introduced a time-based electricity tariff system (TOU) for industrial and commercial consumers but not for residential consumers [3]. Excluding industrial consumers that does not have any specific pattern in their daily load profile, the load profile pattern for residential consumers is different compared to commercial consumers as peak loads usually occur outside working hours [4]. Charging the same TOU electricity tariff for residential consumers will give wrong price signals that may cause unwanted demand responses.

Determining the most optimum TOU price that is fair for both utility and consumers would be the most difficult part in TOU implementation [5]. This is the factors that would determine whether the price can give a clear signal to consumer to change their consumption pattern as desired by the utility that would benefits both of them [6]. Factors like price elasticity, weather and climate are important factors to be considered in designing the optimum TOU electricity prices [7, 8]. However, implementing TOU in the right way could significantly help reducing the total energy consumption cost for customer as well as for the utility [9]. This paper examines the impact of different TOU structures on residential consumers in Malaysia in terms of the optimum TOU prices and load profiles. This will be discussed further in subsequent sections.

\section{RESEARCH METHOD}

This section presents the optimization formulation used to determine the optimum TOU prices for the study. The solid line of Figure 1 shows the actual demand, PdActual for a selected residential area in Malaysia. It can be seen that the demand varies over time and reached its peaks at certain hours throughout the days. The dotted line in the figure represents the desired flat demand, which is named here as average demand, PdAverage and is calculated as follows:

$$
P_{d}^{\text {Average }}=\frac{1}{24} \times \sum_{\text {hour } i=1}^{24} P_{d, \text { hour } i}^{\text {actual }}
$$

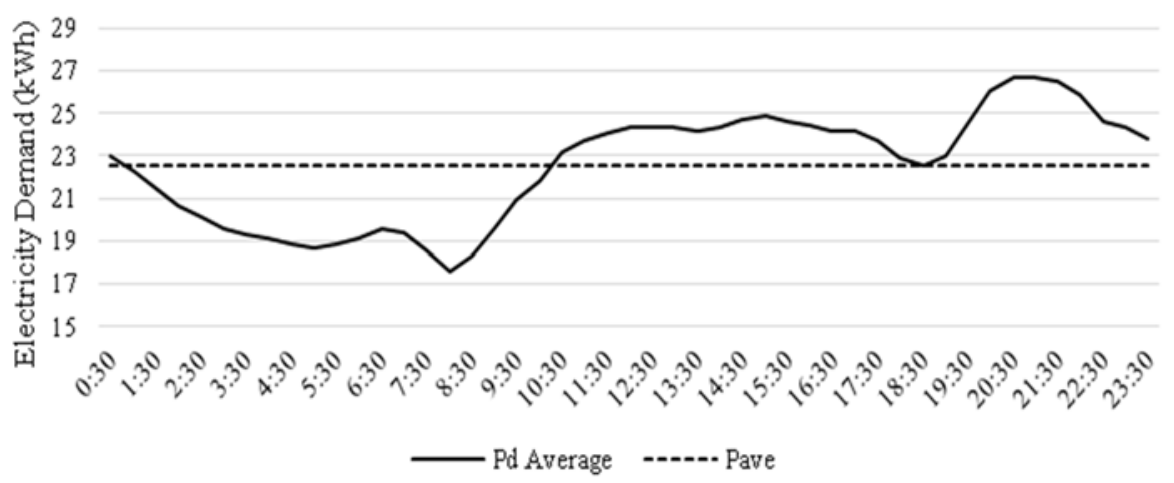

Figure 1. Electricity Demand of a selected residential area in kWh [10]

The main purpose of TOU price is to make the electricity demand pattern as flat as possible [11]. Hence, reducing the electricity consumption during high demand period known as peaks, and increasing consumption during low demand periods. Thus mathematically, the objective of TOU pricing is to minimize the difference between actual demand and average demand, which can be presented as follows [8];

$$
\operatorname{Min}\left\{\sum_{\text {hour } i=1}^{24}\left(P_{d, \text { hour } i}^{\text {Actual }}-P_{d}^{\text {Average }}\right)^{2}\right\}
$$

Price elasticity is an important factor to be considered when setting the TOU prices. Price Elasticity is defined as the sensitivity of demand with respect to the price. The price elasticity at hour i is derived [8];

$$
e_{\text {hour } i}=\frac{\% \Delta P_{d, \text { hour } 1}}{\% \Delta \text { Price }_{\text {hour } i}} \approx \frac{\Delta P_{d, \text { hour } i} / P_{d, \text { hour } 1}}{\Delta \text { Price }_{\text {hour } i} / \text { Price }_{\text {hour } i}}
$$




$$
\begin{aligned}
& \Delta P_{d, \text { hour } i}=\frac{\Delta \text { Price }_{\text {hour } i}}{E_{\text {hour } i}} \\
& \text { where, } E_{\text {hour } i}=\frac{\text { Price }_{\text {hour } i}}{\epsilon_{\text {hour } i} \times P_{\text {d,hour } i}}
\end{aligned}
$$

Since the price elasticity for residential customers in Malaysia is unknown, two price elasticity values will be used in this study. The first price elasticity is -0.02 base on the research work in [12], which is the price elasticity of overall consumers in Malaysia. The second selected price elasticity is -0.27 , which is the mean elasticity of residential customers presented by the research work in [13]. Two elasticity factors are used to represent two different groups of users, a group that responds highly to price changes and a group that does not. TOU price works based on consumer reaction to the price signal. This means that they respond to the price change from the fixed tariff price. In this paper, the fixed price is assumed to be RM0.25. The price change is then defined as the difference between TOU price at a specific time and the fixed tariff price. It is given by;

$$
\Delta \text { Price }_{\text {hour } i}=\text { TOU }_{\text {hour } i}-\text { fixed tariff }
$$

Based on the price changes, it is expected that there are changes in term of actual demand. If the actual demand changes as TOU introduced, it is assumed that it can be written as;

$$
\begin{aligned}
& P_{d, \text { hour } i}^{\text {actual }}=P_{d, \text { hour } i}^{\text {actual,old }}+\Delta P_{d, \text { hour } i} \\
& P_{\text {d.hour } i}^{\text {actual }}=P_{d, \text { hour } i}^{\text {actuald }}+\frac{\Delta \text { Price }_{\text {hour } i}}{E_{\text {hour } i}}
\end{aligned}
$$

Thus, substituting Equation (8) into Equation (2);

$$
\begin{aligned}
& \text { Min }\left\{\sum_{\text {hour } i=1}^{24} \alpha+\beta \Delta \text { Price }_{\text {hour } i}+\gamma\left(\Delta \text { Price }_{\text {hour } i}\right)^{2}\right\} \\
& \text { Where: } \quad \alpha=\left(P_{d, \text { hour } i}^{\text {actual }}-P_{d}^{\text {ave }}\right)^{2} \\
& \beta=2\left(P_{d, \text { hour } i}^{\text {actual }}{ }^{2}-P_{d}^{\text {ave }}\right) / E_{\text {hour } i} \\
& \gamma=\left(1 / E_{\text {hour } i}\right)^{2}
\end{aligned}
$$

This study assumed fair TOU pricing in which the sum of electricity price increment equal to the summation of price decrement. Thus, the objective function in (9) is subjected to the following equality constraint;

$$
\sum_{\text {hour } i=1}^{24} \Delta \text { Price }_{\text {hour } i}=0
$$

It is also assumed that the TOU price for each hour cannot be lower than $50 \%$ of the current fixed price, represented by the following inequality constraint;

$$
\text { TOU }_{\text {hour } i} \geq 0.5 \times \text { fixed tariff }
$$

In this paper, Four TOU pricing structures were analyzed. Each structure consists of different number of blocks. To be more specific, structure 1, 2, 3 and 4 consists of 4, 6, 8 and 12-time blocks respectively. The TOU price for each block is fixed. These price variables are summarized in Table 1. For example, $T_{0} U_{b 1}^{s 1}$ indicates the TOU price for the first-time block of TOU structure 1 , which is fixed for hour 1 to hour 6 . In our mathematical formulation, this constraint is represented as the following Equation;

$$
\operatorname{TOU}_{b 1}^{S 1}=T O U_{\text {hour } 1}=T O U_{\text {hour } 2}=\operatorname{TOU}_{\text {hour } 3}=T O U_{\text {hour } 4}=T O U_{\text {hour } 5}=T O U_{\text {hour } 6}
$$

Other constraints for each time block are written in similar order for each TOU pricing structure. The results are presented in the next section. 
Table 1. TOU price variables for each hour and each TOU pricing structures

\begin{tabular}{|c|c|c|c|c|c|c|c|c|c|c|c|c|c|c|c|c|c|c|c|c|c|c|c|c|}
\hline \multirow{2}{*}{$\begin{array}{c}\text { TOU } \\
\text { structur } \\
\text { e, S }\end{array}$} & \multicolumn{24}{|c|}{ TOU price at hour $\mathrm{i}, T O U_{\text {hour }}$} \\
\hline & 1 & 2 & 3 & 4 & 5 & 6 & 7 & 8 & 9 & $\begin{array}{l}1 \\
0\end{array}$ & \begin{tabular}{l|l}
1 & \\
1 &
\end{tabular} & $\begin{array}{l}1 \\
2\end{array}$ & \begin{tabular}{l|}
1 \\
3 \\
\end{tabular} & 14 & 15 & 16 & $\begin{array}{l}1 \\
7\end{array}$ & $\begin{array}{l}1 \\
8\end{array}$ & $\begin{array}{l}1 \\
9\end{array}$ & 20 & 21 & 22 & $\begin{array}{l}2 \\
3\end{array}$ & $\begin{array}{l}2 \\
4 \\
\end{array}$ \\
\hline $\begin{array}{c}\text { S1(4 } \\
\text { blocks) }\end{array}$ & \multicolumn{12}{|c|}{$T_{O U}^{S 1}$} & \multicolumn{6}{|c|}{$T O U_{b 3}^{s 1}$} & \multicolumn{6}{|c|}{$T O U_{b 4}^{S 1}$} \\
\hline $\begin{array}{c}\text { S2 (6 } \\
\text { blocks) }\end{array}$ & \multicolumn{4}{|c|}{$\operatorname{TOU}_{b 1}^{s 4}$} & \multicolumn{4}{|c|}{$T_{O U} U_{b 2}^{s 4}$} & \multicolumn{4}{|c|}{$T O U_{b 3}^{s 4}$} & \multicolumn{3}{|c|}{$\operatorname{TOU}_{b 4}^{s 4}$} & & \multicolumn{4}{|c|}{$T_{O U}^{s 4}$} & \multicolumn{4}{|c|}{$T_{O U}^{s 4}$} \\
\hline $\begin{array}{c}\text { S3 (8 } \\
\text { blocks) }\end{array}$ & \multicolumn{3}{|c|}{$T_{O U}^{s 4}$} & \multicolumn{3}{|c|}{$T_{O U}^{S 4}$} & \multicolumn{3}{|c|}{$T_{O U}^{s 4}$} & \multicolumn{3}{|c|}{$T O U_{b 4}^{s 4}$} & \multicolumn{3}{|c|}{$T O U_{b 5}^{s 4}$} & \multicolumn{3}{|c|}{$\operatorname{TOU}_{b 6}^{s 4}$} & \multicolumn{3}{|c|}{$T O U_{b 7}^{s 4}$} & \multicolumn{3}{|c|}{$T O U_{b 8}^{s 4}$} \\
\hline $\begin{array}{c}\text { S4 (12 } \\
\text { blocks) }\end{array}$ & \multicolumn{2}{|c|}{$T O U_{b 1}^{s 4}$} & \multicolumn{2}{|c|}{$T O U_{b 2}^{s 4}$} & \multicolumn{2}{|c|}{$T O U_{b 3}^{s 4}$} & \multicolumn{2}{|c|}{$T_{O U}^{S 4}$} & \multicolumn{2}{|c|}{$T_{O U}^{s 4}$} & \multicolumn{2}{|c|}{$T O U_{b 6}^{s 4}$} & \multicolumn{2}{|c|}{$T O U_{b 7}^{s 4}$} & $T O U_{b 8}^{s 4}$ & \multicolumn{3}{|c|}{$T_{O U} U_{b 9}^{s 4}$} & \multicolumn{2}{|c|}{$T_{O U}^{S 4}$} & \multicolumn{2}{|c|}{$T O U_{b 11}^{s 4}$} & \multicolumn{2}{|c|}{$T O U_{b 12}^{s 4}$} \\
\hline
\end{tabular}

\section{RESULTS AND ANALYSIS}

This section presented the results of four TOU pricing structures, namely 4, 6, 8 and 12-time block structure of the optimization problem presented in section 2. Subsection 3.1 presented the optimum TOU price for each hour for each structure, while subsection 3.2 presented the impact of such TOU prices on residential load profiles.

\subsection{TOU Price Results}

Table 2 shows the TOU results for 24 hours for the four TOU pricing structures. For TOU structure 1, the 24 hours is divided into 4-time blocks. The optimum TOU price for each hour is shown in the second column of Table 2 for price elasticity -0.02 and the third column for price elasticity -0.27 . For price elasticity of -0.02 , block 1 and block 2 give the same TOU price of RM0.125. This price is the lowest price based on the constraints set out in equation (14). For block 3, the TOU price is slightly higher at RM0.186 and finally for block 4, the TOU price is the highest at RM0.564. These TOU results indicate that 50\% price decrement from fixed prices for block 1 and 2, while 26\% and 126\% price increment from the fixed price for block 3 and block 4 respectively. Meanwhile, results for elasticity -0.27 show a $42 \%$ and $22 \%$ decrement in price respectively for block 1 and block 2, while price increment of $27 \%$ and 37\% for block 3 and block 4 respectively. Both price elasticities give the same TOU price pattern i.e. low at block 1 and block 2, high at block 3 and the highest at block 4. Basically, the consumer will be charged at high price for 6 hours between 7 pm until 12am.

For TOU structure 2, the TOU prices for block 1, 2, 3 and 5 are the same and at minimum for both elasticity values. Results for elasticity -0.02 show a price increment of $10 \%$ and $190 \%$ for block 4 and 6 respectively. For elasticity -0.27 , a price increment of $96 \%$ and $104 \%$ is showed. For both elasticity values, high TOU price is showed for 4 hours between 9pm until 12am. Comparing with TOU structure 3, high TOU prices is charged at block 7 and 8 (6 hours), which is between 7pm until 12am. Finally, for TOU structure 4, high TOU prices is only charged for 2 hours between 9pm until 11pm, which is at block 11 . Some other blocks are charged with medium TOU prices. From the overall results, it is observed that TOU price structure 4 provides better price signal i.e. the high price is only charged at hours of high demand (from figure 1) specifically at 9pm-11pm and 3pm-5pm.

\subsection{Impact on Load Profile Results}

Figures 2, 3, 4 and 5 show the impact of the four TOU structures on load profile for both elasticity values. For structure 1 as shown in Figure 2, even though the peak demand at 9pm-11pm is reduced, a new peak demand is created around 12pm. The same problem for structure 2 is observed in Figure 3, in which more peak demands are created around 12pm, 5pm and 8pm. Structure 3 and 4 as shown in Figure 4 and 5 respectively, provide better demand profile results. Basically, the electricity demand from 11am until 12am decreases while demand from 12am until 9am increases. Peak demand is reduced, and no new peaks are created. Table 3 shows the maximum demand of the base case and the four TOU pricing structure results. It is observed that structure 3 provides the lowest maximum demand for elasticity value of -0.02 , which is around $2.7 \%$ maximum demand reduction from the base case. On the other hand, structure 4 gives the lowest maximum demand for elasticity value is -0.27 , around $8.9 \%$ reduction from the base case. In other words, if consumer is price responsive, structure 4 will reduce the peak load better then structure 3 . Table 3 summarize the results in term of maximum demand for each of the structure. 
Table 2. TOU tariff for Different Time Blocks

\begin{tabular}{|c|c|c|c|c|c|c|c|c|}
\hline \multirow[b]{2}{*}{ Time } & \multicolumn{2}{|c|}{ Structure 1 (4 blocks) } & \multicolumn{2}{|c|}{ Structure 2 (6 blocks) } & \multicolumn{2}{|c|}{ Structure 3 (8 blocks) } & \multicolumn{2}{|c|}{ Structure 4 (12 blocks) } \\
\hline & $e=-0.02$ & $e=-0.27$ & $e=-0.02$ & $e=-0.27$ & $e=-0.02$ & $e=-0.27$ & $e=-0.02$ & $e=-0.27$ \\
\hline $1: 00$ & 0.1250 & 0.1454 & 0.1250 & 0.1250 & 0.1250 & 0.1887 & 0.1250 & 0.2228 \\
\hline 2:00 & 0.1250 & 0.1454 & 0.1250 & 0.1250 & 0.1250 & 0.1887 & 0.1250 & 0.2228 \\
\hline 3:00 & 0.1250 & 0.1454 & 0.1250 & 0.1250 & 0.1250 & 0.1887 & 0.1250 & 0.1250 \\
\hline 4:00 & 0.1250 & 0.1454 & 0.1250 & 0.1250 & 0.1250 & 0.1250 & 0.1250 & 0.1250 \\
\hline $5: 00$ & 0.1250 & 0.1454 & 0.1250 & 0.1250 & 0.1250 & 0.1250 & 0.1250 & 0.1250 \\
\hline $6: 00$ & 0.1250 & 0.1454 & 0.1250 & 0.1250 & 0.1250 & 0.1250 & 0.1250 & 0.1250 \\
\hline 7:00 & 0.1250 & 0.1939 & 0.1250 & 0.1250 & 0.1250 & 0.1250 & 0.1250 & 0.1250 \\
\hline 8:00 & 0.1250 & 0.1939 & 0.1250 & 0.1250 & 0.1250 & 0.1250 & 0.1250 & 0.1250 \\
\hline 9:00 & 0.1250 & 0.1939 & 0.1250 & 0.1250 & 0.1250 & 0.1250 & 0.1250 & 0.1442 \\
\hline $10: 00$ & 0.1250 & 0.1939 & 0.1250 & 0.1250 & 0.1250 & 0.2669 & 0.1250 & 0.1442 \\
\hline $11: 00$ & 0.1250 & 0.1939 & 0.1250 & 0.1250 & 0.1250 & 0.2669 & 0.1250 & 0.3008 \\
\hline $12: 00$ & 0.1250 & 0.1939 & 0.1250 & 0.1250 & 0.1250 & 0.2669 & 0.1250 & 0.3008 \\
\hline $13: 00$ & 0.1856 & 0.3183 & 0.2749 & 0.4910 & 0.2920 & 0.3197 & 0.1987 & 0.3181 \\
\hline $14: 00$ & 0.1856 & 0.3183 & 0.2749 & 0.4910 & 0.2920 & 0.3197 & 0.1987 & 0.3181 \\
\hline $15: 00$ & 0.1856 & 0.3183 & 0.2749 & 0.4910 & 0.2920 & 0.3197 & 0.3958 & 0.3306 \\
\hline $16: 00$ & 0.1856 & 0.3183 & 0.2749 & 0.4910 & 0.1250 & 0.3027 & 0.3958 & 0.3306 \\
\hline $17: 00$ & 0.1856 & 0.3183 & 0.1250 & 0.1250 & 0.1250 & 0.3027 & 0.1250 & 0.2975 \\
\hline 18:00 & 0.1856 & 0.3183 & 0.1250 & 0.1250 & 0.1250 & 0.3027 & 0.1250 & 0.2975 \\
\hline 19:00 & 0.5644 & 0.3425 & 0.1250 & 0.1250 & 0.5866 & 0.3389 & 0.1250 & 0.3114 \\
\hline 20:00 & 0.5644 & 0.3425 & 0.1250 & 0.1250 & 0.5866 & 0.3389 & 0.1250 & 0.3114 \\
\hline $21: 00$ & 0.5644 & 0.3425 & 0.7251 & 0.5090 & 0.5866 & 0.3389 & 1.2805 & 0.3872 \\
\hline $22: 00$ & 0.5644 & 0.3425 & 0.7251 & 0.5090 & 0.4964 & 0.3330 & 1.2805 & 0.3872 \\
\hline 23:00 & 0.5644 & 0.3425 & 0.7251 & 0.5090 & 0.4964 & 0.3330 & 0.1250 & 0.3124 \\
\hline 24:00 & 0.5644 & 0.3425 & 0.7251 & 0.5090 & 0.4964 & 0.3330 & 0.1250 & 0.3124 \\
\hline
\end{tabular}

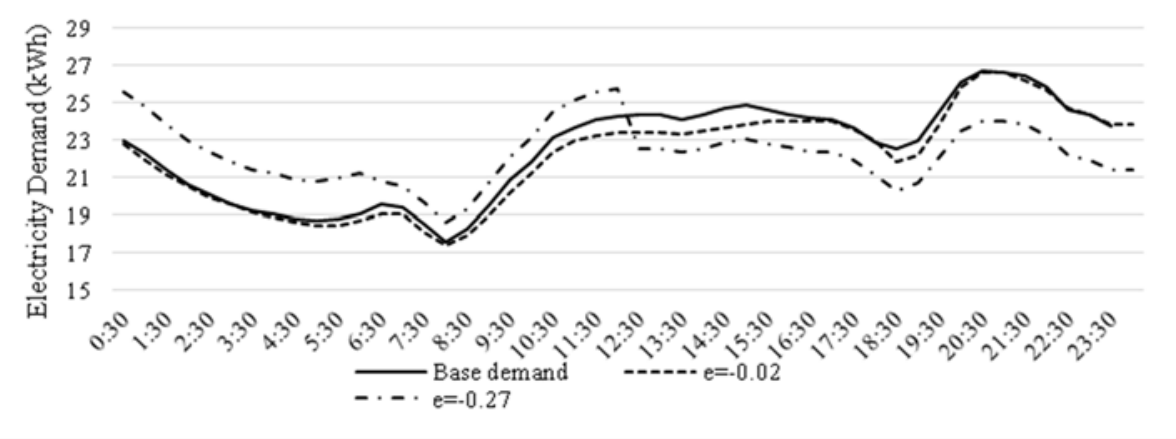

Figure 2. Load profiles for TOU price structure 1 (4-time blocks)

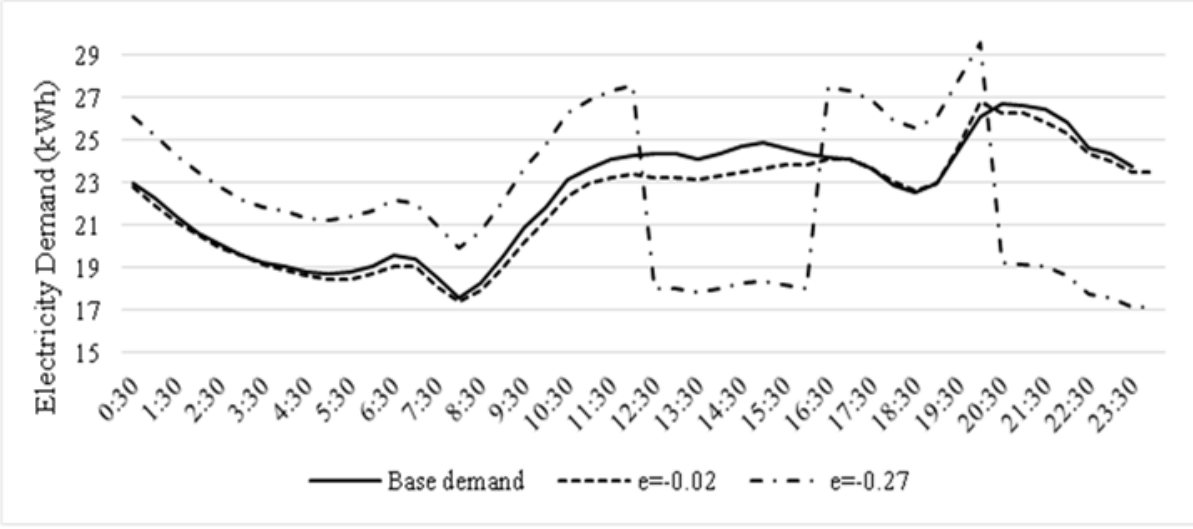

Figure 3. Load profiles for TOU price structure 2 (6-time blocks) 


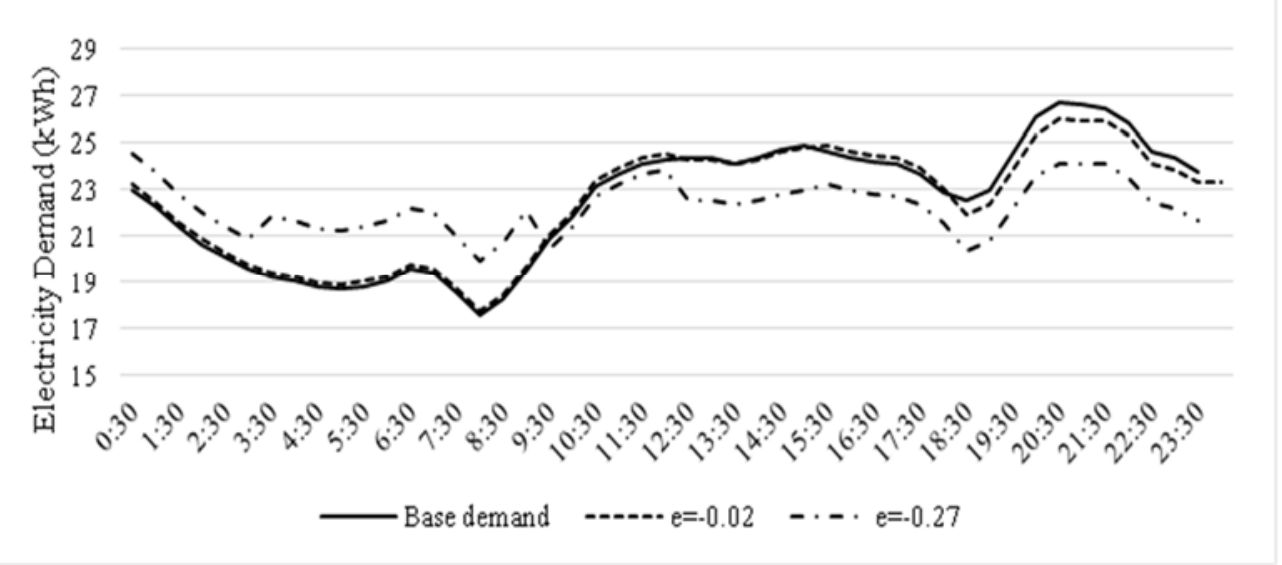

Figure 4. Load profiles for TOU price structure 3 (8-time blocks)

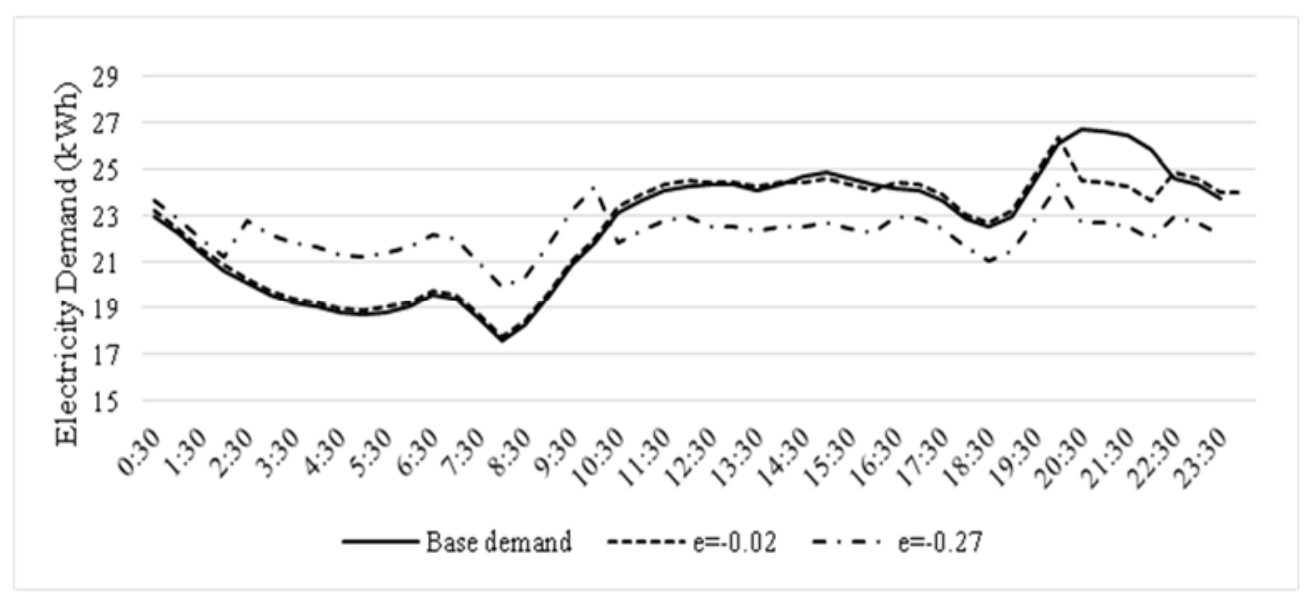

Figure 5. Load profiles for TOU price structure 4 (12-time blocks)

\section{CONCLUSION}

This paper studied the impact of four different TOU electricity pricing structures on TOU prices and load profiles of a residential area in Malaysia. Two elasticity factors are used for each structure to represent two different groups of users. The results conclude that, the TOU structure with 12-time blocks provides better price signals as compared to 4, 6 and 8-time blocks. Also, it can reduce the maximum demand of the base case load profile by $8.9 \%$ for elasticity value of -0.27 .

Table 3. Comparison of Maximum Demand between 4 TOU pricing structures

\begin{tabular}{llc}
\hline Base Case & & $\begin{array}{c}\text { Maximum Demand } \\
26.73 \mathrm{kWh}\end{array}$ \\
\hline Structure 1 & $e=-0.02$ & $26.64 \mathrm{kWh}$ \\
(4 blocks) & $e=-0.27$ & $25.77 \mathrm{kWh}$ \\
Structure 2 & $e=-0.02$ & $26.79 \mathrm{kWh}$ \\
(6 blocks) & $e=-0.27$ & $29.60 \mathrm{kWh}$ \\
Structure 3 & $e=-0.02$ & $26.01 \mathrm{kWh}$ \\
(8 blocks) & $e=-0.27$ & $24.54 \mathrm{kWh}$ \\
Structure 4 & $e=-0.02$ & $26.34 \mathrm{kWh}$ \\
(12 blocks) & $e=-0.27$ & $24.35 \mathrm{kWh}$ \\
\hline
\end{tabular}




\section{ACKNOWLEDGEMENTS}

This work was supported by the Malaysian Ministry of Higher Education (MOHE) and Universiti Teknologi Malaysia (UTM) through Fundamental Research Grant Scheme (FRGS) vot 4F746.

\section{REFERENCES}

[1] N. Loganathan and K. Lakshmi, "Demand Side Energy Management for Linear Programming Method," Indonesian Journal of Electrical Engineering and Computer Science, vol. 14, no. 1, pp. 72-79, 2015.

[2] N. Nazar, M. Abdullah, M. Hassan, and F. Hussin, "Time-based electricity pricing for Demand Response implementation in monopolized electricity market," in Research and Development (SCOReD), 2012 IEEE Student Conference on, 2012, pp. 178-181: IEEE.

[3] T. N. BERHAD. (2016, 4th May 2016). TNB ENHANCED TIME OF USE (ETOU). Available: https://www.tnb.com.my/faq/etou

[4] N. A. M. Azman, M. P. Abdullah, D. M. Said, and F. Hussin, "Enhanced Time of Use Electricity Pricing for Industrial Customers in Malaysia," Indonesian Journal of Electrical Engineering and Computer Science, vol. 6, no. 1, 2017.

[5] R. de Sa Ferreira, L. A. Barroso, P. R. Lino, M. M. Carvalho, and P. Valenzuela, "Time-of-use tariff design under uncertainty in price-elasticities of electricity demand: A stochastic optimization approach," IEEE Transactions on Smart Grid, vol. 4, no. 4, pp. 2285-2295, 2013.

[6] N. Hussin, M. Abdullah, A. Ali, M. Hassan, and F. Hussin, "Residential electricity time of use (ToU) pricing for Malaysia," in Energy Conversion (CENCON), 2014 IEEE Conference on, 2014, pp. 429-433: IEEE.

[7] M. A. Momani, "Factors affecting electricity demand in Jordan," 2013.

[8] W. Lin, B. Chen, S. Luo, and L. Liang, "Factor analysis of residential energy consumption at the provincial level in China," Sustainability, vol. 6, no. 11, pp. 7710-7724, 2014.

[9] M. Sulaima, N. Dahlan, Z. Yasin, N. Asari, and Z. Bohari, "Optimum Enhance Time of Use (ETOU) for Demand Side Electricity Pricing in Regulated Market: An Implementation Using Evolutionary Algorithm," Indonesian Journal of Electrical Engineering and Computer Science, vol. 8, no. 1, 2017.

[10] M. Muzmar, M. Abdullah, M. Hassan, and F. Hussin, "Time of use pricing for residential customers case of Malaysia," in Research and Development (SCOReD), 2015 IEEE Student Conference on, 2015, pp. 589-593: IEEE.

[11] M. P. Abdullah, N. S. M. Nazar, M. Y. Hassan, and F. Hussin, "Optimizing time of use (ToU) electricity pricing in regulated market," Jurnal Teknologi, vol. 78, no. 5-7, pp. 49-54, 2016.

[12] S. Solaymani, S. M. B. Najafi, F. Kari, and N. B. M. Satar, "Aggregate and regional demand for electricity in Malaysia," Journal of Energy in Southern Africa, vol. 26, pp. 46-54, 2015.

[13] P. R. Thimmapuram and J. Kim, "Consumers' price elasticity of demand modeling with economic effects on electricity markets using an agent-based model," IEEE Transactions on Smart Grid, vol. 4, no. 1, pp. 390-397, 2013.

\section{BIOGRAPHIES OF AUTHORS}

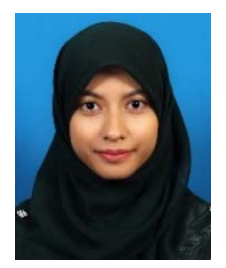

Nur Azrina Binti Mohd Azman is currently a postgraduate student of Faculty of Electrical Engineering, Universiti Teknoloogi Malaysia
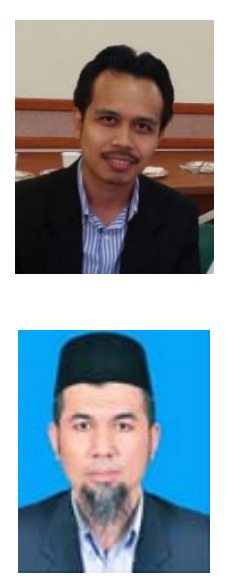

Ir. Dr. Md Pauzi Abdullah is a Senior Lecturer at the Faculty of Electrical Engineering, Universiti Teknologi Malaysia (UTM) and a Research Fellow at the Centre of Electrical Energy Systems (CEES), UTM. He is a Chartered Engineer registered with the Engineering council, United Kingdom, a Professional Engineer registered with the Board of Engineers Malaysia (BEM) and a Certified Energy Manager registered with the ASEAN Energy Management Scheme (AEMAS). He is also a Senior Member of the Institute of Electrical and Electronics Engineers, USA (SMIEEE) and a Corporate Member of the Institution of Engineers Malaysia (MIEM).

Dr Mohammad Yusri Hassan is a Professor at Faculty of Electrical Engineering, Universiti Teknologi Malaysia (UTM). He obtained his B.Eng. in Electrical and Electronic Engineering from University of Strathclyde, United Kingdom in 1988, M.Eng in Electrical Power Engineering from Universiti Teknologi Malaysia in 1994 and PhD in Power System Economics from University of Strathclyde, United Kingdom in 2004. He is the Director of Centre of Electrical Energy Systems (CEES), UTM. 

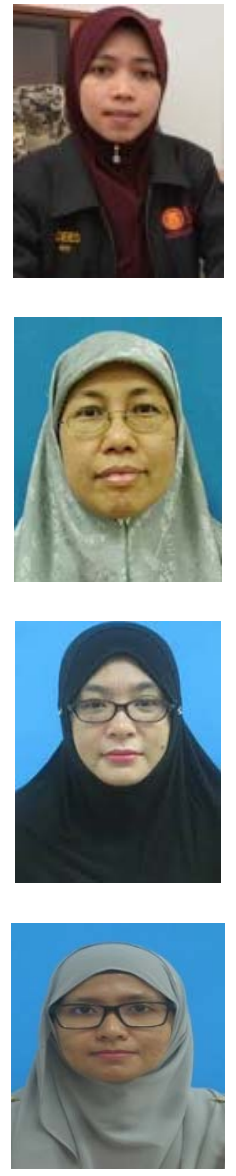

Dr. Dalila Mat Said is a Senior Lecturer at Centre of Electrical Energy Systems, Faculty of Electrical Engineering, Universiti Teknologi Malaysia (UTM). She obtained her B.Eng. in Electrical Engineering in 2000, M.Eng in Electrical Engineering in 2003 and $\mathrm{PhD}$ in Power Quality in 2012 from Universiti Teknologi Malaysia. She has 12 years of experience in teaching electrical engineering courses and supervision of more than 20 undergraduates, and 10 post graduate's students.

Faridah Hussin is a Senior Lecturer at Centre of Electrical Energy System (CEES), Faculty of Electrical Engineering, Universiti Teknologi Malaysia.

Dr Norzanah Rosmin is a Senior Lecturer at Centre of Electrical Energy System (CEES), Faculty of Electrical Engineering, Universiti Teknologi Malaysia.

Dr Siti Maherah binti Hussin is a Senior Lecturer at Centre of Electrical Energy System (CEES), Faculty of Electrical Engineering, Universiti Teknologi Malaysia. 